\title{
"A INTIMIDADE PENUMBROSA": NOTAS SOBRE A ESCRITA DE SI EM AL BERTO¹
}

\author{
Leonardo de Barros Sasaki \\ (Universidade de São Paulo)
}

\section{RESUMO}

A pergunta que enfrentamos é sobre a relação entre vida e poesia em uma obra, como a do poeta Al Berto, tão permeada pela dita escrita de si (autobiografia, diário íntimo, memórias, correspondência, etc.). O artigo propõe-se a discutir noções como as de privacidade, intimidade e autenticidade. Para isso, comentaremos não apenas os textos literários stricto sensu, como também declarações públicas - entrevistas e discursos -, entendendo-as como parte do "jogo autobiográfico" proposto pelo poeta. Ao fim, como estudo de caso, analisaremos dois textos relativamente desconhecidos de Al Berto: "Nota biográfica em forma de carta" e "Discurso de agradecimento ao Prémio de Poesia do P.E.N. Club” - ambos por nós recolhidos no espólio do poeta.

PALAVRAS-CHAVE: Al Berto, intimidade, escrita de si.

\section{ABSTRACT}

The question we face is how can we understand the relationship between life and poetry in a work like the one by the poet $\mathrm{Al}$ Berto, so permeated by so-called self-writing (autobiography, diary, memoirs, correspondence, etc.). The intention in this article is to discuss the notions of autobiography, privacy, intimacy and authenticity in his poetic universe. For that, we comment not only the literary texts stricto sensu, as well as his public statements - interviews and speeches -, understanding them also as part of the "autobiographical game" proposed by the poet. At the end, we propose, as a case study, the analysis of two somewhat unknown texts by Al Berto: "Biographical note in letter form" and "Acceptance Speech for the PEN Club Award for Poetry", both collected by us in the poet's estate.

KEYWORDS: Al Berto, intimacy, self writing. 
Em entrada de 13 de dezembro de 1982 de O Medo, Al Berto afirma: "um dia começarei a redigir um diário, mas ainda é cedo, um diário requer entrega total, um rigor, uma disciplina, de que não sou capaz" ( $\mathrm{AL}$ BERTO, 2009, p. 234). De imediato, já temos o flagrante sinal de um jogo, de uma tensão - Al Berto lembra-nos: isto não é um diário. Daí, podemos desdobrar algumas perguntas que nortearão este artigo: Como o poeta evoca e desloca os gêneros autobiográficos? Como pensar, por exemplo, as noções de intimidade, privacidade e autenticidade, a partir dessa relação tensionada com tais gêneros? Afinal, observada a construção da persona Al Berto, não haveria um "rigor", uma "disciplina" de outra natureza nessa obra?

Manuel de Freitas, ao estudar os três volumes (pseudo) diarísticos de $O$ Medo, percebe a coexistência de apontamentos prosaicos, característicos do diário, e de momentos assumidamente líricos. Isso põe em discussão a pertinência da taxonomia dos gêneros e leva-nos, antes, a pensar em estratégias de hibridização e simulação das modalidades autobiográficas "canônicas”. De qualquer forma, "o que parece não oferecer dúvida” concluímos com Freitas - "é a preferência (quando não obsessão) por uma escrita autobiográfica” (FREITAS, 2005, p. 23; grifo do autor).

O pano de fundo para tal discussão é o predomínio, na contemporaneidade, do espaço da privacidade e da intimidade. ${ }^{2}$ Talvez seja pertinente, destarte, fazermos considerações quanto aos vocábulos "intimidade" e "privacidade", antecipando, contudo, que assim procedemos mais para levantar questões e menos em uma tentativa de sistematização rigorosa - o que, em última instância, é infrutífero do ponto de vista da análise a ser desenvolvida.

Quem propõe uma distinção é a socióloga madrilena Helena Béjar (1988, p. 200) em El ámbito íntimo. Ela aponta como, em espanhol tal qual em português, "privacidade" é um neologismo derivado do privacy inglês, que, por sua vez, significa, segundo o Oxford English Dictionary, "a state or condition of being withdrawn from the society of others". Para ela, a referência a esse distanciamento, a esse insulamento implica uma área ou zona em que o indivíduo deseja estar solitário. É, por isso, uma noção espacial ligada, principalmente - mas não só -, ao ambiente doméstico.

Já "intimidade" deriva do superlativo latino intimus, isto é, "o mais afastado, o mais recôndito; o âmago, o mais secreto”. Diz respeito, portanto, a uma instância outra, mais adiante, mais profunda do que a da privacidade. Nela, encontram-se os atributos, questionamentos e sentimentos mais particulares de uma existência, o que faz de "intimidade", por conseguinte, uma noção mais psicológica.

Claro está que, ao fim e ao cabo, a distinção é operativa, já que os vocábulos ocorrem de maneira imbricada e muito de nossa análise trabalha nessa dupla chave da privacidade e da intimidade. Em História da vida privada, Orest Ranum (1991, p. 214-234), por exemplo, utilizará a etiqueta "refúgios da intimidade" para designar os locais de recolhimento - tais 
como a casa, o quarto, o jardim, o escritório, etc. No caso de Al Berto, acreditamos haver uma conjugação do domínio privado com a sondagem íntima, isto é, com a objetivação da intimidade. Abundam os exemplos em que os espaços encarnam predicativos humanos como extensões do sujeito poético: "passei a considerá-la [a casa] como um órgão do meu corpo" (AL BERTO, 2009, p. 226).

Nesse sentido, não negligenciamos a declaração do poeta feita à revista Ler: "E a casa é sempre o centro e o sentido do mundo. A partir daí, da casa, percebe-se tudo. Tudo. O mundo todo" (AL BERTO, 1989b, p. 15, grifos nossos). Tal afirmação é um contraponto incitador a leituras que exclusivamente atrelem - e delimitem - a obra de $\mathrm{Al}$ Berto à vivência do urbano.

Colhemos outro exemplo expressivo no texto "No silêncio dos jardins” (AL BERTO, 2007, p. 66). Nele, recupera-se o antigo topus do “jardim" como ambiente do privado em intersecção com metáforas do corpo; é o "jardim interior" da intimidade, com seus "afectos e ódios", com sua zona recôndita de "obscuridade e penumbras":

Encontrar-nos-emos nas imagens deste jardim de afectos e de ódios. Porque os jardins são labirínticas arquitecturas mentais, onde podemos resguardar os corpos de qualquer voragem do tempo (...) Mas se um dia regressares, passeia-te por dentro do meu corpo. Descobrirás o segredo deste jardim interior - cuja obscuridade e penumbras guardam intacto o nocturno coração (AL BERTO, 2007, p. 66)

O que nos parece incontornável é recorrência - ou quase onipresença, a partir de Salsugem - do que Leonor Arfuch resolve por chamar de "espaço da interioridade", ou seja, "não só o espaço interior do pensamento e da afetividade, mas também o âmbito físico da moradia" (ARFUCH, 2010, p. 40).

Não se pode perder de vista, porém, que intimidade e privacidade são dados moventes, que se articulam a diferentes valores e interpretações ao longo da história. Para Diana Klinger, no campo literário contemporâneo, as obras que circulam pelo íntimo "inscreve[m]-se no coração do paradoxo deste final de século XX: entre o desejo narcisista de falar de si e o reconhecimento da impossibilidade de exprimir uma 'verdade' na escrita." (KLINGER, 2007, p. 26, grifos nossos).

Um ponto de partida fecundo para examinarmos o movediço da escrita de si é o gênero da entrevista, pois, como ressalta Arfuch, ele condensa algumas das fixações de nosso tempo: "a compulsão de realidade, a autenticidade, o 'ao vivo', a presença", com a finalidade de "encontrar uma verdade" (ARFUCH, 2010, p. 23; grifos da autora).

As perguntas que transcreveremos a seguir guardam uma similaridade interessante: a necessidade de constatação ou de autenticação da "verdade" - perceptível na tentativa de verificá-la, por parte dos entrevis- 
tadores, mesmo quando o poeta discorre sobre o caráter essencialmente mutável da autorrepresentação.

Em entrevista ao Público, quando perguntado sobre a "única paixão da vida", o poeta responde: "A única paixão da minha vida foi alguém que tinha um olhar de violeta estarrecida, mas acho que houve mais flores, não me lembro". Dá-se, então, o diálogo: “Já contou alguma mentira?” - “Já, o que acabei de responder." - "Por quê?" - "Porque se calhar é mesmo verdade." (AL BERTO, 1991, p. 29). Em outra entrevista, agora para o Expresso, temos acesso à seguinte conversa: "Compreendi que, ao longo dos anos, foi a obra que exigiu de mim uma imagem sempre renovada. E através dessa imagem, ou de imagens sucessivas, foi-se erguendo o retrato daquele que escreve" - "É verdade?" - "Claro que pode ser uma mentira, mas há mentiras esplêndidas e verdades bem ranhosas" (AL BERTO, 1987a, 52R).

Para já, fica demonstrado de que maneira, em Al Berto, o gênero da entrevista precisa ser entendido enquanto um paratexto considerável, já que muitas afirmações, pouco objetivas, são assimiladas à poesia ou dela partem: "o único território que sinto ainda ser meu é a imensa noite do Mundo" (AL BERTO, 1987a, p. 52R) está, por exemplo, na "paixão de quem atravessa a noite/ do mundo" (AL BERTO, 2009, p. 323) ou "a escrita conduz-me ao silêncio" (AL BERTO, 1997a, p. 20) em "a escrita é minha primeira morada de silêncio" (AL BERTO, 2009, p. 256).

Queremos pleitear com isso que o texto da entrevista passa a integrar a obra dentro da esfera das escritas de si como estratégia de constituição do sujeito ${ }^{3}$ - tal qual está, por exemplo, a produção epistolar para a obra de Sá-Carneiro. Outro exemplo, que analisaremos adiante, estaria no discurso, a priori do "autor empírico", de agradecimento do Prémio do P.E.N. Club, por sua dicção preponderantemente poética e pela ancoragem nas imagens e temas de sua obra.

Rosa Maria Martelo denominou de "efeito global de autenticidade" (MARTELO, 2010, p. 83) o frequente intratexto entre a prosa e a poesia de Al Berto. Acrescentaríamos ainda: esse efeito, para além da expressão escrita, alberga outras instâncias - como as referidas declarações públicas e também os seus retratos. ${ }^{4}$ 


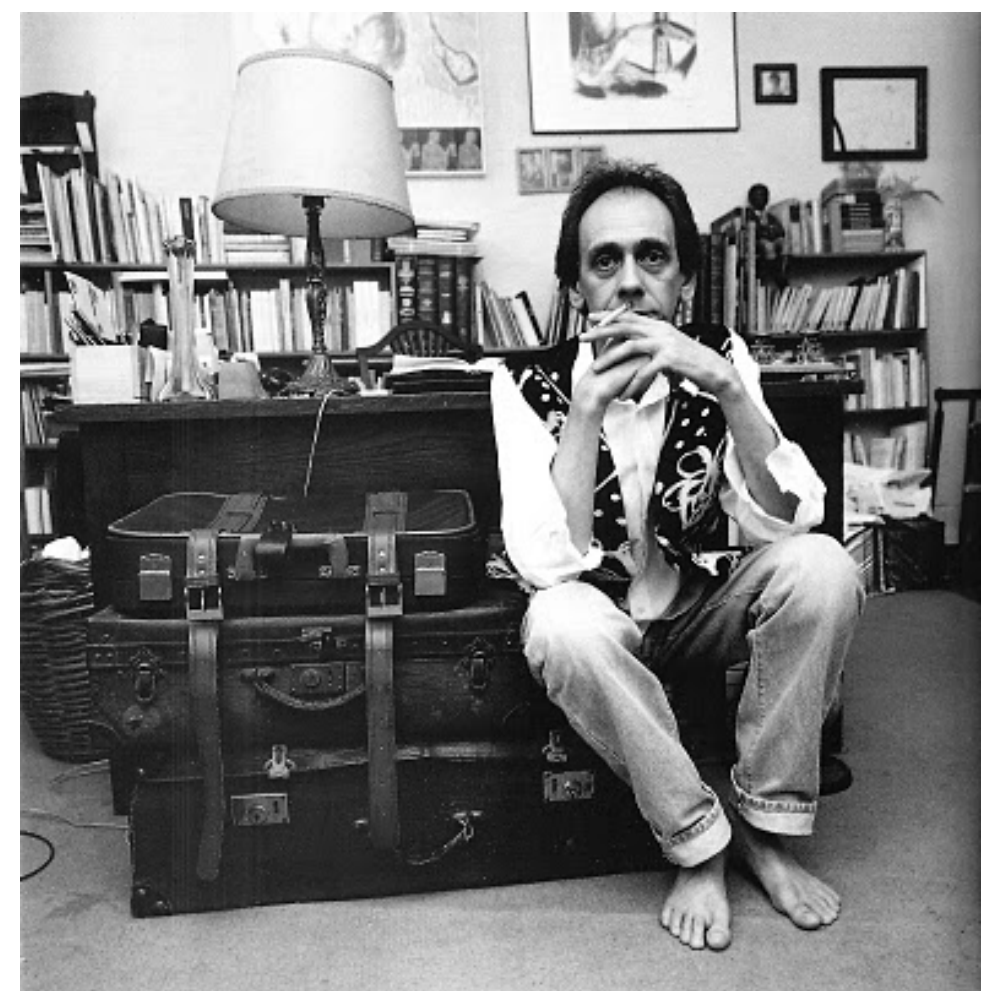

Figura 1 Retrato de Al Berto por Luísa Ferreira, 1996

Luísa Ferreira, em Retratos e poemas (1998), propôs-se a fotografar poetas, sugerindo-lhes, a princípio, que expusessem o seu local de trabalho (cf. Figura 1). Quando comparado aos demais, o retrato de Al Berto é dos mais peculiares, por bastante simbólico: ${ }^{5}$ aparece fumando em seu apartamento em Lisboa, sobre malas de viagem - elemento tão evocativo de traços de sua poesia: a "incitação à fuga" (AL BERTO, 2009, p. 167), a "transumância da vida" (2009, p. 233), a "vida como um barco à deriva” (2009, p. 637).

Em entrevista ao Público, adverte: "Há um rigor, uma coerência inabalável naquilo que escrevo, e na minha vida.” (AL BERTO, 1991, p. 29; grifos nossos). Al Berto voltará a se pronunciar de modo semelhante "Não consigo separar a vida e a literatura e vice-versa. Está tudo profundamente ligado. Para mim é assim: tem de haver uma grande coerência na maneira como se escreve, como se vive, como se está no mundo, senão nem a vida, nem a poesia fazem qualquer sentido" (AL BERTO, 1997a, p. 20). Ora, a "grande e inabalável coerência" é o outro nome para o "efeito global de autenticidade" que Martelo encontrou. O poeta não se aplica ao obstinado rigor do verbo, mas a um rigor performático, diríamos, que faz da obra um trabalho de composição nos diversos âmbitos de expressão do sujeito.

Klinger, ao analisar a prosa contemporânea brasileira, percebe dinâmica análoga em que é possível

entrever o caráter teatralizado da construção de imagem de autor (...), [em que] tanto os textos ficcionais quanto a atuação (a vida pública) do autor são faces complementares da mesma produção de uma subjeti- 
vidade, instâncias de atuação do eu que se tensionam ou se reforçam, mas que, em todo caso, já não podem ser pensadas isoladamente. (KLINGER, 2007, p. 55, grifos da autora)

Parece ser exatamente isso que está contido no depoimento: "Acho que sou um escritor e vivo como um escritor. Para além daquilo que escrevo inventei-me um cenário de escritor" (AL BERTO, 1989a, p. 22). Al Berto fazia desse "cenário" uma espécie de "ritual da escrita": "Gosto de manter todos os instrumentos do ritual vivos: papéis, canetas, o cheiro da tinta, o fabuloso mata-borrão" (AL BERTO, 1994, p. 4). Em outra entrevista, o caráter teatral é mais evidente: "Fascina-me assumir a vida de 'escritor', com todos seus rituais. Não só os próprios, mas os dos outros" e cita, então, as "pantufas de Tennessee Williams" e a "bengala de Borges" (AL BERTO, 1993, p. 8). Ora, essa "ritualização" da persona do poeta passa a ser mais reveladora de uma atitude poética, performática, do que propriamente reveladora do homem ou de sua intimidade "verdadeira" ou "autêntica".

Foi no Romantismo que a ideia de autenticidade passou a ter grande relevo. "La autenticidad", assevera Béjar, "se relaciona con la unicidad y con una excelencia que confiere el sentimiento de ser único, singular, superior a la copia, a lo múltiple”. As marcas da Ilustração - o artifício, a convenção e o disfarce - ganham má-fama nessa sociedade em que "apariencia y personalidad se identifican hasta el punto de creer que la conducta se revela de forma involuntaria y se desvela antes incluso que el conocimiento de uno mismo" (BÉJAR, 1988, pp. 190-191). ${ }^{6}$ Aí está o princípio da sociedade íntima que, em certa medida, ainda é a nossa.

O periódico Critical Inquiry trouxe, em seu $24^{\circ}$ volume, um dossiê dedicado ao privacy na contemporaneidade. Lauren Berlant, editora que assina o texto "Intimacy: a special issue", divide conosco o desafio de entender "the pedagogies that encourage people to identify having a life with having an intimate life", tamanha a proeminência da intimidade. $\mathrm{O}$ reflexo mais visível dessa equiparação é, continua Berlant, "a fantasy that private life is the real in contrast to collective life: the surreal, the elsewhere, the fallen, the irrelevant" (BERLANT, 1998, p. 282-283)7.

Richard Sennett (1988), no que denominou de "declínio do homem público", defende que um dos sustentáculos da "ideologia da intimidade" é a crença de que a proximidade entre as pessoas é um bem moral. Em outras palavras, as relações sociais estão baseadas na eleição de um pequeno grupo de indivíduos com os quais é possível aproximar-se através de uma contínua troca de revelações, de confissões. A lógica, grosso modo, seria: quanto maior acesso à intimidade, mais próximo se está do indivíduo ou, mais precisamente, do eu autêntico do indivíduo.

O princípio instituidor da fórmula está igualmente no Romantismo, sendo as Confissões de Rousseau um paradigma, conforme apontou Jean Marie Goulemot: 
em vez de propor que a verdade se encontra na razão, ou mesmo que é inspirada por Deus, Rousseau tenta definir moralmente o lugar da enunciação (...) A relação com a verdade pertence à categoria da visão e da revelação (...), provém do íntimo (apud ARFUCH, 2010, p. 50)

A entrevista, a depender de seu encaminhamento, inclui-se nessa dinâmica, se considerada a abertura da intimidade de um autor. Seria, assim, um aproximar-se do leitor pela revelação da "verdade", de uma verdade íntima; e é nesse ponto que a situação se complica. Voltemos às entrevistas de Al Berto. Pergunta-se: “é verdade?”, ele responde "pode ser mentira”; pergunta-se: "já mentiu?", ele responde: "o que acabei de responder". Quebra-se, portanto, o princípio de que a exposição do íntimo é concomitante à exposição de uma verdade. Melhor dito: o regime de verdade do poeta não é o dos modelos teóricos da correspondência; não tem esse compromisso. A palavra poética cria uma realidade, e é por isso que, no instante em que é pronunciada, "se calhar é mesmo verdade".

Quando o poeta diz: "escrevo para sobreviver /como quem necessita partilhar um segredo" (AL BERTO, 2009, p. 541), não está em causa a "verdade" íntima, mas uma revelação estabelecida pela e na escrita. Podemos pensar, então, em uma poesia que se utiliza de "vestígios" (aparentemente) factuais ou referenciais para criar um efeito - de autenticidade ou, se o quisermos, de intimidade -, no qual vida e obra se confundem.

Se toda verdade é antes uma verdade poética, não olvidemos que sempre haverá ainda, como citamos, as penumbras do "jardim interior", sua zona do "enigma", do "segredo" dessa intimidade, esfera do jamais traduzível: "no fundo, sou um homem sentado, a escrever, num recanto inacessível do meu próprio corpo" (AL BERTO, 2009, p. 459), conclui o poeta. Ao tratar dos caminhos contemporâneos dos escritos íntimos em seu basilar ensaio "O secreto e o real", Paula Morão distingue o "enigma e o segredo como elementos fulcrais para a vida íntima, tão mais importantes quanto se estendem não só a quem lê, mas, e talvez sobretudo, a quem escreve" e acrescenta "a natureza do enigma reside no segredo da própria linguagem, e na luta travada entre um $e u$ que se quer conhecer dizendo-se e a obscuridade da palavra" (MORÃO, 2011, p. 49). Não está em questão apenas a dimensão insondável de uma vida, mas a insanável contingência dos próprios canais de sua expressão.

Al Berto, em texto sintomaticamente intitulado "Ressaca para uma autobiografia", toca nesse ponto: "dois mistérios insolúveis: viver e escrever. E ambos estavam intimamente ligados que, provavelmente, se conseguisse desvendar um deles, o outro sê-lo-ia também." (AL BERTO, 2012, p. 62, grifos nossos). Logo, a escrita íntima, por sua condição, tem de conviver com qualquer coisa de essencialmente indecifrável, de indizível - o exato oposto, portanto, da presunção de que o contínuo e aprofundado ato de revelar-se atingiria, em algum momento, o ser autêntico ou alguma verdade do sujeito. 
Sob essa perspectiva, coloca-se uma pergunta central: de que maneira pode-se falar, então, em intimidade na obra de um contemporâneo como Al Berto? Se falamos em "intimidade", poderíamos juntar outros termos a ela relacionados, tais como "narcísico", "confessional" ou "autobiográfico". Seria desnecessário apontar este ou aquele crítico que referende tais adjetivos, já que não há "rótulo", entre esses, que não esteja assentado pela recepção crítica de $\mathrm{Al}$ Berto. E acrescentaríamos: não há rótulo que o próprio $\mathrm{Al}$ Berto não aceite $\mathrm{e}$, em certa medida, não reclame para sua obra - seja por meio de entrevistas, seja por meio do próprio texto literário. Para determo-nos apenas nas entrevistas, que são mais pontuais, citamos as afirmações: no Diário de Notícias: "[O narcisismo] existe, mas não sei se da forma como analisaram" e, mais adiante, quando questionado se assumia o confessionalismo, "Sim, mesmo que seja um tique de geração" (AL BERTO, 1997b, p. 32); e, na Ler: "A primeira referência, para qualquer coisa que se escreve, é biográfica” (AL BERTO, 1989b, p. 13).

Não se trata de negá-los, mas de discuti-los, relativizá-los, matizá-los, já que tão facilmente eles ocorrem para descrever sua obra. Em outras palavras, é dentro de um contexto de instabilidade e transgressão que o poeta frequenta os gêneros, temas e procedimentos estilísticos ligados à intimidade. Por isso, convém meditarmos sobre a "obsessão" de Al Berto por habitar um "espaço biográfico".

Utilizamos aqui expressão de Leonor Arfuch, que, por sua vez, deslocou-a a partir de Philippe Lejeune para, justamente, distinguir-se dele. O teórico francês recorria a tal noção para superar a exemplaridade e a modelização de sua (malograda) procura por uma especificidade do gênero autobiográfico. Com a expressão, ele pretendia, inclusive, abarcar formas biográficas que excediam a literatura. Arfuch justifica o empréstimo da seguinte maneira, à qual aderimos:

uma espacialização (...) onde confluíam num dado momento formas dissimilares, suscetíveis de serem consideradas numa interdiscursividade sintomática, por si só significantes, mas sem renunciar a uma temporalização, a uma busca de heranças e genealogias, a postular relações de presença e ausência. (ARFUCH, 2010, p. 22, grifos da autora)

Fica claro, portanto, que esse espaço não é "concebido como um reservatório onde cada espécime fornece um 'exemplo"' (ARFUCH, 2010, p. 22); não é um ponto de chegada, mas de partida, considerado a partir de uma tradição de escritas de si, na qual se operam linhas de continuidade e de deslocamento.

Há de se ter em conta também a "interdiscursividade sintomática”, que são os traços dos gêneros autobiográficos que, apesar dos elementos desconstrutivos, ainda remetem a "outro regime de verdade, a outro horizonte de expectativa”, como sintetiza Arfuch - sua lógica é central para nossa pesquisa e, por isso, vale a longa citação: 
Efetivamente, nem o descentramento do sujeito operado pela psicanálise, nem as distinções introduzidas pela teoria literária - a não identificação entre autor e obra; os procedimentos de ficcionalização compartilhados, por exemplo, com o romance; o triunfo da verossimilhança sobre a veracidade etc. -, nem a perda de ingenuidade do leitor/receptor 'modelo', treinado já na complexidade midiática do simulacro, levaram, no entanto, a uma equivalência entre os gêneros autobiográficos e os considerados de 'ficção'. A persistência aguda desta crença, esse algo a mais, esse suplemento de sentido que se espera de toda inscrição narrativa de uma 'vida real', remete a outro regime de verdade, a outro horizonte de expectativa. (ARFUCH, 2010, p. 72-73, grifos da autora)

Arfuch entende o apelo da 'vida real', cada vez mais perceptível em nossos dias, esse "tempo de incertezas", como signo da "busca da plenitude da presença - corpo, rosto, voz - como proteção inequívoca da existência, da mítica singularidade do eu" (ARFUCH, 2010, p. 74, grifos da autora) - o que cria uma atmosfera de maior e mais fácil adesão ao texto pelo leitor. Recuperando a noção de "autenticidade", no mesmo sentido vai Clara Rocha, para quem

A escrita do eu pode assim ser encarada como uma forma de salvação individual num mundo que começa a descrer de sucessivos modelos ideológicos de salvação colectiva. E para muitos a vivência da intimidade é uma garantia de autenticidade num tempo em que a vida pública se tornou uma espécie de 'teatro do mundo.' (ROCHA, 1992, p. 19, grifos nossos)

A reflexão de ambas as autoras está centrada em uma produção eminentemente em prosa. Acreditamos ser possível estabelecer paralelos no campo poético: se o imperativo modernista da impessoalidade na poesia - como é o caso de Mallarmé, Eliot e Pessoa, por exemplo - colocava em causa a subtração de qualquer vestígio de presença do autor, a vertente poética dominante pós-70, em Portugal, procurou um investimento naquele "algo a mais" de que falava Arfuch.

No entanto, é preciso matizar, sob a ótica da poesia albertiana, a proliferação de produções no espaço biográfico como garantia de autencidade, como mecanismo de ultrapassagem do vazio identitário sentido pelo público leitor. Sobre isso, Arfuch retoma a concepção lacaniana de "sujeito como 'puro' antagonismo, auto-obstáculo, autobloqueio, limite interno que impede realizar sua identidade plena" e conclui que "se o sujeito só pode encontrar uma instância 'superadora' desse vazio em atos de identificação, a identificação imaginária com o outro e com a vida do outro é o ato mais 'natural"' (ARFUCH, 2010, p. 77; grifos da autora). O objeto da identificação, como ressalva Arfuch, não necessariamente tem de ser algo modelar ou glamoroso, mas pode ser também "certa falha, debilidade, culpa do outro". 
Por um lado, existe uma dimensão referencial na obra que torna plausível esse movimento - em Al Berto, na chave da "falha". Por outro lado, em sua dimensão metalinguística, autorreflexiva, na qual o poeta (se) nega qualquer posição estável dentro de sua própria obra, os “atos de identificação" daquele que lê só existem se o drama do autor - o de se realizar textualmente - for transplantado para o plano empírico da constituição identitária de um leitor que vive no contexto da contemporaneidade e de sua fragmentação, de sua carência de unidade.

À esperança de que Clara Rocha falava - e a afirmação parece cabível tanto à produção, como à recepção - em "salvação individual" por meio da escrita, o poeta responde: "escrita não é salvação" (AL BERTO, p. 29).

Dito de outra maneira, o cunho íntimo de sua poesia mostra-se assim mais complexo do que os rótulos quando apressadamente imputados. O poeta não ignora a herança problematizadora que Arfuch enumera e, ao invés de esquecê-la, prefere instalar sua poesia no centro mesmo do paradoxo, do "enigma", “do mistério insolúvel” e de suas inescapáveis oscilações.

Percebe-se daí a ambivalência da afirmação/ocultação do sujeito, em que simultaneamente reclama uma posição enunciativa biográfica - em seus atos de identificação e protocolos de leitura -, ao mesmo tempo em que, forçosamente, coloca sua poesia em terreno instável, no qual a expressão íntima, paradoxalmente, não joga luz sobre o sujeito poético, mas o ensombra e o descentra. Consoante, Morão ensina:

o eu entra na dialéctica entre os princípios de concentração e dispersão, dividido entre um força centrípeta e uma força centrífuga. Nem sempre é fácil reencontrar o caminho para casa depois de tamanho esforço de fragmentação, nem sempre é fácil voltar à interpretação global da vida. (MORÃO, 2011, p. 51)

Dessa maneira, ainda que isso exceda os limites deste ensaio, interessa-nos não apenas passar em revista a dimensão tensionada da construção textual do sujeito e de sua intimidade, mas também ter por horizonte o trânsito mesmo nesse "espaço biográfico" da contemporaneidade, buscando inseri-lo em certa crítica à cultura da ordem, da banalização da subjetividade e da coisificação da experiência humana. Por isso que, quando questionado se a escrita é "só um acto intimista" - ao que parece entendido como concernente unicamente ao próprio sujeito -, Al Berto responde: "Porque suspeito que alguém que escreve, e reflecte sobre aquilo que escreve, está acima de sua efémera condição humana. Funciona talvez como uma câmara de eco do Mundo" (AL BERTO, 1987b, p. 3, grifos nossos).

O principal impasse que de imediato se impõe reside na própria abrangência do poder da linguagem, nas limitações dessa "câmara de eco" - isto é, a falta de reverberação da voz do sujeito no mundo em que vive. A respeito da questão, Manuel de Freitas percebe uma "desilusão ontológica e referencial ou, mais prosaicamente, a consciência de quão pouco as palavras dizem ou reflectem o que chamamos 'vida'” (FREITAS, 2005, p. 24). 
Al Berto deixa-se marcar por um desencanto quanto à capacidade das palavras de apreenderem o que quer que seja - daí a associação com o falso: "mascaro os dias com palavras cujo significado eu perdi" (AL BERTO, 2009, p. 334), "surge a escrita: essa mentira" (2009, p. 459) e "depois continuamos pela orla branca do papel/ regressamos felizes à falsidade das palavras/ mas já não conseguimos ser os mesmos/ que ali tinham vivido e amado" (2009, p. 508). Percebe-se uma ambiguidade no tratamento dessa impossibilidade: é essencialmente negativa a constatação, mas pode ser também o engano necessário, o "regresso feliz", mesmo que ele esteja estigmatizado pelo desencanto da impossibilidade - "mas já não conseguimos".

É como se, mesmo não sendo um homem ordinário, por vezes aceitasse a livsløgn ibseniana, ou seja, a mentira que é a condição para uma "existência de papel”. Nesse sentido, Pinto do Amaral não foi menos preciso em falar no "fingir o esquecimento" (AMARAL, 1991, p. 50) - textualmente dito em $O$ anjo mudo: "Atraiçoam-me [as palavras]. Mas, apesar de tudo, continuo a fingir que acredito nelas. Uso-as com a convicção firme de quem acaba de descobrir qualquer coisa e dela se apropria. É tudo mentira, claro" (AL BERTO, 2012, p. 22; grifos nossos).

Dito de outra maneira, o poeta aceita a condição irresolúvel do impasse e escreve apesar dele, com ele e a partir dele: "escrever podia ser um vício feliz/ ou a única mentira suportável" (AL BERTO, 2009, p. 354). Se as palavras não abarcam toda a realidade e estão fadadas à inutilidade: "pelo corpo condeno-me à vida/ de susto em susto à inutilidade da escrita” (2009, p. 541), esses últimos versos nos habilitam conjecturar que elas, então, aparecem orientadas ou perspectivadas por uma pulsação que "condena" o poeta "à inutilidade da escrita": essa pulsão, em Al Berto, é o medo.

Como ressalva Clara Rocha,

o estatuo representativo da escrita e o carácter selectivo do texto autobiográfico são duas razões maiores para que o impasse seja sem solução. Ao escrever (sobre) a sua vida, o sujeito constata que a narrativa é um 'transfert', e que, por mais que a dilate, nunca ela lhe restitui plenamente a totalidade do vivido. (ROCHA, 1992, p. 26; grifos nossos)

Sumariza a autora: "[o texto] é um sinal de vida, mas não é vida" (ROCHA, 1992, p. 26, grifos nosso); Al Berto concorda, diz em entrada de 22 de janeiro de 1984: "a escrita resume muito mal o que retemos da vida, quase nada, um quantos sinais vertiginosos, umas quantas dores." (AL BERTO, 2009, p. 362)

Pensar nos "sinais vertiginosos", nas "quantas dores" já nos dá pistas de um viés ou de um recorte representativo - "de susto em susto" - do sujeito e da realidade por ele experimentada, como dirá em outro momento: "por trás de cada poema existe o corpo que o gerou num instante de pânico” (AL BERTO, 2009, p. 233). Em outros versos, Al Berto lembra aquilo 
que "dos corpos a escrita tenta guardar:/ pequenos ossos caídos no fogo das emoções" (2009, p. 580), ou seja, o corpo escrito constitui-se de vestígios do sujeito, daqueles "sinais vertiginosos" que - para nos mantermos no mesmo campo semântico dos versos - funcionam como o combustível dessa poesia, associado aos afetos, que os inflamam.

Os "sinais vertiginosos", "os pequenos ossos", entendidos como os rastros ou fragmentos do sujeito, serão novamente tematizados nos dois textos que selecionamos para uma análise mais detida - a saber: "Nota biográfica em forma de carta" e "Discurso de agradecimento ao Prémio de Poesia do P.E.N. Club". A leitura deles ajuda-nos a melhor demonstrar as questões teóricas anteriormente suscitadas.

O primeiro intitula-se "Nota biográfica em forma de carta" e foi escrito a pedido do tradutor para edição italiana de Lavori dello sguardo, de 1985. Trata-se de documento autógrafo, datado de novembro de 1984. Começa:

Fico sempre embaraçado quando tenho de falar de mim. Por outro lado, parece-me irrelevante esboçar o trajecto duma vida que, sinceramente, eu tantas vezes confundo com a vida dos poemas. Assim, seduz-me mais a ideia de abandonar, ao acaso, algumas pistas ao correr desta carta $[\ldots]$

Nasci em 1948, a 11 de janeiro na cidade de Coimbra [...] Mas é um mero acaso ter nascido em Coimbra. Poderia ter nascido em Harrar onde Rimbaud traficava armas e esquecia Verlaine, enquanto a gangrena alastrava. (AL BERTO, 1985, p. 39) ${ }^{9}$

Embora o texto tenha fortes indicadores da escrita de si - não bastasse ser uma "nota biográfica", é ainda "em forma de carta" -, as primeiras linhas problematizam um relato autobiográfico pensado de forma canônica, pois, de pronto, evita uma declaração que "fale de si" frontalmente, algo que, admite, "o embaraça”. Esse impasse estará também em O Medo: "sou um homem que se evita, um homem cujo nome se perdeu e cuja biografia possível está no pouco que escreveu” (AL BERTO, 2009, p. 457). Eis o emaranhado: a "biografia possível" é a de um "homem que se evita".

Mais adiante, na "Nota biográfica", irá acrescentar: "É-me impossível elaborar uma nota autobiográfica normalizada." (AL BERTO, 1985, p. 40; grifos do autor). Assumir tal "normalização" seria ir à contramão do que representa a obra e seu efeito de intimidade, seria determinar uma clara dualidade entre vida e obra - instâncias que Al Berto prefere manter "confundidas". O que (o) seduz em sua obra é a possibilidade de deixar "pistas", que jamais comporão a biografia de um sujeito - assim como nessa "nota biográfica" não se saberá de $\mathrm{Al}$ Berto, já que este gostaria de "tagarelar noite adiante sobre as virtudes do mel, ou sobre as abelhas de Virgílio, nascidas do sangue do touro imolado, ou dizer nomes de rios e de cidades até que o sono me abatesse dentro do meu próprio esquecimento." (1985, p. 40) 
O texto poético poderá misturar-se a ele, mas não está confinado aos limites biográficos de Alberto Pidwell Tavares, que nasceu em Coimbra, mas "poderia ter nascido em Harrar" assim como em qualquer outra localidade que a poesia fundasse.

Não há verdade a ser buscada, não há verdade a ser encontrada através da correspondência factual, conforme irá repetir no excerto a seguir: "Ficou-me a lucidez, a solidão que de novo vou povoando com imagens, visões, lugares imaginados, sussurros, ausências... Mentiras que se transmudam em verdades assim que as escrevo. É melhor assim!" (AL BERTO, 1985, p. 39-40, grifos nossos)

Ao indivíduo solitário e lúcido, na impossibilidade de qualquer inteireza, resta dedicar-se à coleção de vestígios evanescentes do real. $\mathrm{O}$ sujeito "em pistas", “em sinais”, não raro recorrerá às enumerações, que parece ser o mecanismo mais adequado para quem vê (e dá a ver) a si e ao mundo por meio de fragmentos - que serão citados textualmente em nova ocorrência enumerativa:

Talvez daqui a muitos anos eu consiga abarcar o sinuoso rastro deixado pelo meu corpo. Por enquanto só vislumbro fragmentos, dúvidas, breves olhares, esquecimentos, minúsculas claridades, vertiginosas paixões, corpos que se me revelam inabitados, sorrisos muito nítidos (...) (AL BERTO, 1985, p. 40)

A enumeração indicia também o inventário da poesia - seu interesse, sua matéria-prima -, que recolhe "dúvidas", "olhares", "esquecimentos", "paixões", "corpos", "sorrisos”. Deles, denota-se a importância basilar do corpo e dos afetos para essa poesia; são elementos evocadores do íntimo.

Contudo, de maneira inesperada, o vocábulo “intimidade" é ele mesmo esquivo na obra e ocorre propriamente, até onde temos conhecimento, uma única vez n'O Medo: "o peito desgasto pela doença. por uma fenda nas madeiras cresce a alba. perfura, entra pela janela, devassa a intimidade penumbrosa do quarto. paro de escrever, estou muitíssimo cansado. na exaustão da noite dei comigo a enumerar as coisas amadas." (AL BERTO, 2009, p. 132).

Nesse excerto, chamamos a atenção para o ambiente característico do íntimo: o sujeito solitário, insone, escrevendo exaustivamente em seu aposento, enumerando, e repetimos, enumerando "as coisas amadas". O que interrompe esse processo é a chegada da manhã, dos primeiros raios de sol que invadem a casa, que "devassa[m] a intimidade penumbrosa do quarto". Notemos que a intimidade não se refere exatamente ao sujeito, mas é extensível ao seu ambiente privado, naquela intersecção de que falávamos. É uma imagem bem conseguida para pensarmos a questão de uma escrita da intimidade e do seu possível paradoxo. Afinal, a mais fiel, a mais sincera, a mais "autêntica" das escritas íntimas estaria, em tese, aberta a essa devassa da claridade, da transparência. Entretanto, revelar-se - e eis 
o paradoxo - é justamente despir a intimidade daquilo que a constitui, de sua natureza recôndita.

Cessar a escrita justamente quando se lança luz ao íntimo é sintomático. A intimidade deve ter seu terreno de penumbra, que não significa obscurantismo. O binômio exposição/ocultação de uma intimidade furtiva está igualmente presente no segundo texto escolhido.

Trata-se de datiloscrito autógrafo, datado de 14 de junho de 1988, quando do recebimento do Prémio de Poesia do P.E.N. Club. ${ }^{10} \mathrm{O}$ documento é inédito e encontra-se no espólio do poeta sob a seguinte identificação: “E.49, caixa 39”.

O dado curioso que impressiona logo na primeira leitura é que, diferentemente do esperado para um autor tão afirmativo da primeira pessoa, aqui, em situação ainda mais centrada em sua figura, em um evento público, prefere o discurso em terceira pessoa. Tal escolha funciona como subterfúgio para evitar o simples "falar de si", que "o embaraça", conforme dito na "Nota biográfica". Al Berto, nesse sentido, vai além: opta por uma fala de forte carga poética, calcada na repetição de temas comuns a sua poesia:

Numa ilha de vegetação rente ao mar, um homem vive entre o regresso cauteloso das estações e a sedimentação lenta do sal [no] silêncio das palavras.

Os dias repetem-se no estremecer da luz, e o mistério de incandescentes criaturas perturba-lhe o repouso nocturno, e o sonho.

Ao levantar-se com a manhã sente-se cercado pelo perfume quente das acácias e pelo canto dos galos. Vive ali, rodeado de coisas efémeras que se acumularam na memória, numa relativa solidão.

Aqui vemos, assim como nas demais ambientações supracitadas, o sujeito apartado do mundo e dos homens, no paroxismo da privacidade, a viver a repetição dos gestos, dos dias, das estações. Está atento ao detalhe das flores, dos animais. Permanece insone na companhia dos resíduos da memória.

Essa atmosfera pacata é, então, interrompida: "Um dia levanta-se e bebe café. $\mathrm{O}$ telefone toca, alguém que comunica que ganhou um prémio. (...) O tempo e a erva invadiram-no, da mesma maneira vagarosa que em si cresce a alegria.”. Desconhece, no entanto, a possibilidade de compartilhar a surpresa e a alegria - a tal alegria que lhe cresce atrelada à consciência do tempo passado observável nas ervas daninhas crescidas ao pé da casa.

Há, no discurso, duas estratégias bastante recorrentes em Al Berto a serem consideradas. Num primeiro momento, há o entrelaçamento de um dado aparentemente biográfico, que de imediato instaura um "efeito de intimidade" - no caso, confidencia jamais ter ganhado prêmio, com exceção de um aos quinze anos. 
Em um segundo momento, determinada informação descentra toda a construção anterior: "sem se levantar da cadeira, perto do telefone, caminhou, ou pensou caminhar, por entre as árvores de um poema”. Assim, retroativamente, podemos nos perguntar: ele conhece ou pensa conhecer as "glicínias enlouquecidas" de um poema?; ele é perturbado ou pensa o ser por "incandescentes criaturas" de um poema?; e, por fim, ele vive ou pensa viver "numa ilha de vegetação" de um poema? Não interessa a resposta porque justamente não interessa sua correspondência factual.

É preciso interrogar-se sobre o efeito de intimidade para essa poesia, o que parece ligado às afirmações finais do discurso:

Por fim, ergueu os olhos e viu os hibiscos tremeluzirem na luminosidade limpa da manhã. Sem se levantar da cadeira, perto do telefone, caminhou, ou pensou caminhar, por entre as árvores de um poema. Fechou os olhos, a pouco e pouco deixou-se comover, e acreditou que era precisamente essa comoção, situada algures acima de si mesmo, que hoje, de modo inesperado, [seria] reconhecida.

Quem está sendo premiado? Seria o poeta virtuose e seu rigor formal, sua ourivesaria poética? Para ele que confidencia - com alguma falsa modéstia - "saber pouco ou nada de Poesia"? Talvez fosse melhor perguntar: o que está sendo premiado?

Está dito: "A comoção, situada algures acima de si mesmo". Essa obra, assim, espera ser lida, espera ser reconhecida por sua comoção, por sua capacidade de afetar, despertar afetos, por sua capacidade de "com-mover", de mover-se com, de mover-se perto, "como quem necessita partilhar um segredo" (AL BERTO, 2009, p. 541). Logo, a intimidade deve ser lida por algo que a escapa, que está "algures acima" do próprio poeta. Essa comoção, a da partilha, excede aos possíveis biografemas identificáveis.

A intimidade em Al Berto é um efeito; como no Caravaggio que encenou, é uma composição em chiaroscuro repleta de presenças e ausências - sobretudo ausências; é um exercício doloroso e exaustivo de recolher "pistas" que ora se encaixam, ora se perdem. Tanto faz: não está em questão desvendar o segredo, mas partilhá-lo com aqueles que se comovem. Daí a seguinte afirmação constante da "Nota biográfica": "Queimo os dias a esboçar outras realidades e a tentar partilhá-las com alguém. Mas é muito difícil. Leila, numa carta, escreveu a Mountolive: tudo o que me resta é o que partilho contigo: uma existência de papel" (AL BERTO, 1985, p. 40).

\section{REFERÊNCIAS BIBLIOGRÁFICAS}

AL BERTO. Lavori dello Sguardo. Tradução de Carlo Cattaneo. Roma: Florida, 1985.

. “Os néons e a noite do mundo". Expresso. Lisboa, 17 de out., 1987a. 
_ "Sou um homem insone". Jornal de Letras. Lisboa, 19 de out., 1987b. jan., 1989. “Al Berto: entrevista sem fim”. Diário de Lisboa. Lisboa, 27 de . [Entrevista]. Ler: livros e leitores. Lisboa, n. 5, 1989a.

. “Aprendo a odiar meus inimigos”. Público, Lisboa, 15 de jan., 1991.

out. 1993

. "Há gente demais a escrever poesia". Público, Lisboa, 22 de . “Até ao extremo". Diário de Notícias, Lisboa, 20 de mar., 1994. . "O poeta como viajante". Jornal de Letras, Lisboa, 23 de abr., 1997a. de abr., 1997b.

. "Dor e silêncio das ruas vazias". Diário de Notícias, Lisboa, 26 _. O Medo (trabalho poético 1974-1997). Lisboa: Assírio \& Alvim, 2009.

. Dispersos. Lisboa: Assírio \& Alvim, 2007.

. O Anjo Mudo. Lisboa: Assírio \& Alvim, 2012.

AMARAL, Fernando Pinto do. O mosaico fluido. Lisboa: Assírio \& Alvin, 1991.

ARFUCH, Leonor. O espaço biográfico. Rio de Janeiro: EdUERJ, 2010.

BÉJAR. Helena. El ámbito intimo. Madrid: Alianza, 1988.

BERLANT, Lauren. "Intimacy: A Special Issue”. Critical Inquiry. Chicago, 24, n. 2, 1998.

CORBIN, Alain. O segredo do indivíduo. In: PERROT, Michelle et al. História da vida privada: da Revolução Francesa à Primeira Guerra. v. 4 São Paulo: Companhia das Letras, 1991.

DUBY, Georges. A emergência do indivíduo. In. ARIÈS, Philippe et al. História da vida privada: da Europa feudal à Renascença. v. 2, São Paulo: Companhia das Letras, 1990.

FERREIRA, Luísa. Retratos e poemas. Lisboa: Teorema, 1998.

FREITAS, Manuel de. Me, Myself and I. Lisboa: Assírio \& Alvin, 2005.

GIRARD, Alain. Évolution sociale et naissance de l'intime. In: Intime, Intimité, Intimisme. Lille: Éditions Universitaires de Lille III, 1976.

GUERREIRO, António. Sobre um retrato de Al Berto. Jornal de Letras. Lisboa, 21 de ago., 1984. 
KLINGER, Diana. Escritas de si, escritas do outro: o retorno do autor e a virada etnográfica. Rio de Janeiro: 7Letras, 2007.

MARTELO, Rosa Maria. Uma escrita da luz e da sombra. In: PINHARANDA, João (org.). A secreta vida das palavras. Sines: Centro Cultural Emmerico Nunes, 2010.

MORÃO, Paula. O secreto e o real. Lisboa: Campo das comunicações, 2011.

RANUM, Orest. Os refúgios da intimidade. In: História da vida privada 3: da Renascença ao século das luzes. São Paulo: Cia das Letras, 1991.

ROCHA, Clara. Máscaras de Narciso. Coimbra: Almedina, 1992.

SASAKI, Leonardo de Barros. Decifrar os sinais da intimidade: leituras de Al Berto. São Paulo: Universidade de São Paulo, 2012. (Dissertação de Mestrado em Letras - Literatura Portuguesa).

SENNETT, Richard. O declínio do homem público: as tiranias da intimidade. São Paulo: Companhia das Letras, 1988.

TODOROV, Tzvetan. O jardim imperfeito. São Paulo: Edusp, 2005.

Recebido para publicação em 06/05/2013

Aprovado em 30/07/2013

\section{NOTAS}

1 Ensaio elaborado a partir de excerto do primeiro capítulo de nossa dissertação, Decifrar os sinais da intimidade: leituras de Al Berto. O texto foi modificado e ampliado para esta publicação.

2 Não é nosso interesse traçar uma diacronia do desenvolvimento da ideia de intimidade e privacidade. Registramos, todavia, algumas referências: "A emergência do indivíduo" de George Duby, "Os refúgios da intimidade" de Orest Ranum, "O segredo do indivíduo" de Alain Corbin - os três integrantes da coleção História da vida privada -, "Evolution sociale et naissance de l'intime" de Alain Girard em Intime, intimité, intimisme e O jardim imperfeito de Tzvetan Todorov. Todos constam da bibliografia.

3 Ainda sobre as entrevistas, faz-se necessária uma nota profilática. Ainda que em nenhum momento tenha sido a metodologia adotada - sequer insinuada -, explicitamos que as entrevistas não são utilizadas enquanto chave analítica per se, o que denotaria servilismo de nossa leitura a uma suposta "intencionalidade" do autor, aqui jamais perseguida. As entrevistas figuram enquanto dado complementar e assimilado à obra e, portanto, são subalternas à verificação textual - e não o inverso.

4 As capas dos livros de Al Berto são exemplos disso - sendo a de O Medo sua demonstração maior. Indicamos, sobre isso, o ensaio "Sobre um retrato de Al Berto" de António Guerreiro acerca da fotografia de Paulo Nozolino na primeira edição de Salsugem (AL BERTO, 1984, p. 14-15).

5 Pelo impacto simbólico, fomos levados a questionar se o retrato havia sido sugestão de Ferreira. Relatou-nos, entretanto, que deu total liberdade para os escritores escolherem o local da fotografia. O retrato segue reproduzido (cf. Figura 1) com a devida autorização da autora. A ela, mais uma vez, agradecemos a recepção e a disponibilidade. 
6 "A autenticidade se relaciona com a unicidade e com uma excelência que confere o sentimento de ser único, singular, superior à cópia, ao múltiplo" e "aparência e personalidade se identificam até o ponto de se crer que a conduta se revela de forma involuntária e se desvela mesmo antes do conhecimento do indivíduo" [versões nossas]

7 "as pedagogias que encorajam as pessoas a identificar ter uma vida com ter uma vida íntima" e "a fantasia de que a vida privada é a real em contraste com a coletiva: o surreal, o outro-lugar, o caído, o irrelevante" [versões nossas]

8 Ambos são constantes do espólio do autor. Reportamo-nos ao levantamento realizado durante estágio de pesquisa na Biblioteca Nacional de Portugal. Os resultados estão publicados, como apêndice, em nossa dissertação, cuja referência completa inclui-se na bibliografia.

9 Citamos a versão em português que consta do espólio do poeta, mas as indicações remetem, para fins de consulta, ao texto traduzido para o italiano, tal qual foi publicado.

10 Versão manuscrita em francês deste texto foi lida, segundo indicação do poeta, no Grande Anfiteatro da Sorbonne em 8 de Novembro de 1988. 